\title{
GHRH-R Expression Level under Hyperglycaemic Like Culture Conditions in Breast Cancer Cell Lines
}

\author{
Sara Hesham Amer Awad ${ }^{1,2}$, Mira Emad EIDin Abd El Aal Mohammed Ibrahim ${ }^{1,2}$, Gazala Afreen Khan ${ }^{3}$ and Samrein BM Ahmed $^{1,2^{*}}$ \\ ${ }^{1}$ College of Medicine, University of Sharjah, Sharjah, UAE \\ ${ }^{2}$ Sharjah Institute for Medical Research, University of Sharjah, Sharjah, UAE \\ ${ }^{3}$ Dubai Pharmacy College, Dubai, UAE
}

"Corresponding author: Samrein BM Ahmed, College of Medicine, Sharjah Institute for Medical Research, University of Sharjah, Sharjah, P.O Box 27272, United Arab Emirates, Tel: 0097165057223; E-mail: samahmed@sharjah.ac.ae

Received date: December 06, 2017; Accepted date: January 12, 2018; Published date: January 19, 2018

Copyright: (c) 2018 Amer Awad SH, et al. This is an open-access article distributed under the terms of the Creative Commons Attribution License, which permits unrestricted use, distribution and reproduction in any medium, provided the original author and source are credited.

\begin{abstract}
Background: Diabetes mellitus (DM) is a complex disease and increments in its prevalence have been reported in the last few years. DM does not only affect the cells by disturbing glucose metabolism, but also it leads to serious health disorders such as cardiac ischemic diseases, hypertension, and infertility. Intriguingly, DM was also found to mediate cancer development and progression. The exact mechanism of how hyperglycemia affects cancer cells is still obscure. Growth hormone releasing hormone receptor (GHRH-R) is a G-protein coupled receptor that was shown recently to enhance breast cancer cells proliferation. Moreover, a recent work revealed that $\mathrm{GHRH}-\mathrm{R}$ is upregulated in diabetes mellitus in a rat model. It was of interest to investigate whether hyperglycemic conditions have any impact on the GHRH-R expression in breast cancer cell lines, which might then affect the cell proliferation.
\end{abstract}

Methods: MDA MB 231 and T47D breast cancer cell lines were treated with either $15 \mathrm{mM}$ glucose or $15 \mathrm{mM}$ fructose. The expression of GHRH-R was assessed by western blotting and immunofluorescence. The proliferation of the cells was studied by MTT assays.

Results and discussion: The generated data showed that the GHRH-R affected MDA MB 231 and T47D breast cancer cell lines proliferation upon growth hormones treatment but not under hyperglycemic conditions. The results suggested that GHRH-R might mediate breast cancer cells proliferation and survival among other factors.

Keywords: Hyperglycemia; Breast cancer; GHRH receptor; Glucose; MTT assay; Proliferation

\section{Introduction}

Diabetes mellitus (DM) is a cumbersome disease that affects different cellular functions through glucose metabolism commotion. Intriguingly, DM was found to mediate cancer development and progression [1-3]. In diabetic patients, cancer may be favored by hyperglycemia, hyperinsulinemia or anti-diabetic drugs $[1,4,5]$. Moreover, diabetes might exacerbate cancer via influencing hormonal homeostasis, which might affect hormone related cancers [6]. The exact mechanism of how diabetes leads to cancer is still obscure.

Growth hormone releasing hormone receptor (GHRH-R) is a Gprotein coupled receptor that was reported recently to enhance breast cancer cells proliferation. Previous studies have shown that in the pituitary, the binding of GHRH to its receptor activates the Alphasubunit (G-AlphaS) of the closely associated G-Protein complex, thus, stimulating membrane-bound AC (Adenylyl Cyclase) and increasing intracellular cAMP (cyclic Adenosine Monophosphate) concentrations. cAMP binds to and activates the regulatory subunits of PKA (Protein Kinase-A), which in turn releases catalytic subunits that translocate to the nucleus and phosphorylate the cAMP rresponse eelement binding (CREB) protein, known transcription factor. Phosphorylated CREB, together with its coactivators, p300 and CBP (CREB Binding Protein) enhances the transcription of various genes by binding to specific DNA elements within gene promoter regions, referred to as CREs (cAMP-Response Elements). The genes that were activated by GHRH and cAMP contain CREs in their promoter regions. CREB, via direct and indirect mechanisms, stimulates $\mathrm{GH}$ production via transcription of the $\mathrm{GH}$ gene as well as increasing transcription of the GHRH-R gene as part of a short positive feedback loop [7].

In addition to this neuroendocrine action, accumulated evidence implies additional roles for GHRH receptor in carcinogenesis in nonpituitary tissues [8-11]. In vitro and in vivo studies have shown that splice variant 1 (SV1) of the GHRH receptor, which is widely expressed in non-pituitary tissues and cancers, can mediate the proliferative effects of GHRH $[10,12]$. GHRH-R SV1 lacks a short extracellular portion of the full-length receptor, was shown to mediate the mitogenic effects of GHRH and to possess ligand-independent activity in stimulating cell proliferation. The exact mechanism is not yet known [8]. Research has proved the expression of SV1 of the GHRH receptor on breast cancer cell lines $[8,10]$. Moreover, a recent work revealed that GHRH-R is upregulated after 2 days streptozotocin treatment in a rat model [13]. Keeping these facts into consideration, it was of interest to investigate whether hyperglycemic conditions have any impact on the GHRH-R expression in breast cancer cell lines, which might affect the cell proliferation. 


\section{Materials and Methods}

\section{Cell lines}

T47D and MDA MB231 were gifted by Dr. Salem Chouaib of the Institut de Cancérologie Gustave Roussy-Villejuif, France. MDA MB 231 cells were maintained in Dulbecco Modified Eagle's medium DMEM (Gibco; 61965) supplemented with 10\% Foetal bovine serum (Gibco; 10270), and penicillin $(100 \mathrm{U} / \mathrm{ml}) /$ streptomycin $(100 \mu \mathrm{g} / \mathrm{ml})$ antibiotic mixture (Gibco; 15140). The cells were left to grow in a humidified incubator provided with $5 \% \quad \mathrm{CO}_{2}$. The cells were dissociated from the dish when these reached $90-100 \%$ confluence using 1x Trypsin/EDTA (Gibco; 15400). All the mammalian cell culturing was performed under aseptic conditions. T47D were maintained in DMEM/F12 ham medium supplemented with the above reagents in addition to 0.2 Units/ml Insulin (10516-Sigma).

\section{Hyperglycemic conditions}

The cells were plated on 6-wells plate and after $24 \mathrm{hrs}$ the cells were starved by adding DMEM plus $0.5 \%$ serum for $24 \mathrm{hrs}$. The cells were i) left starved for more $24 \mathrm{hrs}$ followed by DMEM (10\% serum) addition or ii) DMEM/0.5\% serum supplemented with $15 \mathrm{mM}$ Glucose or Fructose for $24 \mathrm{hrs}$ or $48 \mathrm{hrs}$.

\section{Protein extraction}

The cells were washed with pre-chilled PBS and lysed with triton lysis buffer (50 mM Tris, $150 \mathrm{mM} \mathrm{NaCl}, 5 \mathrm{mM}$ EGTA, 1\% Triton-X100 and just before use $1 \mathrm{mM}$ PMSF (phenylmethylsulfonyl fluoride). 1.0 $\mathrm{mM} \mathrm{Na} \mathrm{VO}_{4}, 50 \mathrm{mM} \mathrm{NaF}$ plus protease inhibitor cocktail $(1 / 100)$ (8340-Sigma) was added to the cells and incubated with the cells for 20 min on ice to solubilise the phospholipid membranes. The cell lysates were then spun down at $14,000 \mathrm{rpm}$ for $20 \mathrm{~min}$ at $4^{\circ} \mathrm{C}$ to get rid of the insoluble materials.

\section{Western blotting}

Equal amount of proteins was loaded on 10\% DS-PAGE gel. The proteins were then transferred to a PVDF (Imibilon), using a BioRad semi-dry transfer apparatus at $22 \mathrm{~V}$ for $90 \mathrm{~min}$. The membrane was blocked with $5 \%$ milk in PBST for $1 \mathrm{hr}$; followed by anti-GHRH-R antibody (ab28692; abcam-UK) incubation at $4^{\circ} \mathrm{C}$. The membrane as washed and anti-Rabbit HRP was then added (ab191866; abcam-UK). The membrane was developed using enhanced Chemiluminescence kit from thermoscientific (32106; USA). The membrane was stripped and re-probed with the anti-GAPDH antibody (ab37168; abcam-UK). The statistical analyses were performed using Image J and Excel, 2010.

\section{Immunofluorescence}

The cells were seeded on sterile acid-treated coverslips for $24 \mathrm{hrs}$. The cells were then starved for $24 \mathrm{hrs}$. Next day, the cells were either incubated with DMEM contained 0.5\% FBS, DMEM contained 10\% FBS, DMEM contained $0.5 \%$ FBS plus $15 \mathrm{mM}$ glucose or DMEM contained $0.5 \%$ FBS plus $15 \mathrm{mM}$ fructose for 24 hrs. The cells were then washed with PBS and fixed with $3.8 \%$ formaldehyde for $10 \mathrm{~min}$. This was followed by cell saturation and permeabilization of the cells with $0.1 \%$ Triton for $10 \mathrm{~min}$ at room temperature. The anti-GHRH-R antibody (ab28692; abcam-UK) was added in a dilution of 1:200 in 1\%
BSA in PBST and incubated overnight at $4^{\circ} \mathrm{C}$. The anti-GHRH-R antibody was detected by goat anti-rabbit IgG H\&L (Alexa Fluor ${ }^{\circledR} 488$ ) for $1 \mathrm{hr}$ at room temperature. The cells were then visualized by fluorescence microscope (Olympus, BX51TF) and the images were acquired using cellSens Standard software.

\section{MTT assay}

The cells were counted by TC 20 Biorad automated cell counter and 75000 cells were plated on flat bottom 96 wells plate. After $24 \mathrm{hrs}$, hyperglycemic conditions were applied as aforementioned. Fresh medium with the required treatments were added supplemented with $0.5 \mathrm{mg} / \mathrm{mL}$ of MTT reagent (Thermo Fischer) and the cells were incubated for $4 \mathrm{hrs}$ at $37^{\circ} \mathrm{C}$. After removing the medium, $50 \mu \mathrm{L}$ of DMSO was added and the readings were taken at $540 \mathrm{~nm}$. Statistical analysis was performed by Excel, 2010.

\section{Results}

\section{Hyperglycemia effect the expression of GHRH-R on T47D and MDA MB 231 breast cancer cell lines}

One of the key elements in DM pathology is hyperglycemia. Hyperglycemia was shown to disturb the cell machinery yielding distorted biological responses. In previous reports hyperglycemia was found to induce proliferation. Accordingly, it was hypothesized that hyperglycemia might induce breast cancer proliferation via GHRH-R overexpression. To test our hypothesis, two breast cancer cell lines (T47D and MDA-MB231) were starved and then treated with $10 \%$ serum containing medium, $0.5 \%$ serum containing medium, $15 \mathrm{mM}$ glucose in $0.5 \%$ serum containing medium or $15 \mathrm{mM}$ fructose in $0.5 \%$ serum containing medium for $24 \mathrm{hr}$. Protein expression levels of GHRH-R were assessed by western blotting (Figure 1A). GHRH-R expression was significantly elevated when the cells were treated with $10 \%$ serum, while $15 \mathrm{mM}$ glucose treatment resulted in slight increase in T47D but not in MDA MB 231 (Figures 1A and 1B).

\section{Assessing the expression of GHRH-R in T47D and MDA MB 231 under hyperglycemic conditions by immunofluorescence}

GHRH-R expression was further tested by immunofluorescence technique. T47D and MDA MB 231 cells were treated as aforementioned. The cells were fixed, permeabilised and stained for GHRH-R (green) and the nuclei were stained with DAPI (blue). In T47D cells, the GHRH-R expression demonstrated an elevation in both $15 \mathrm{mM}$ glucose-treated cells and in the cells incubated with $10 \%$ serum containing medium when compared with the cells treated with $0.5 \%$ serum containing medium and fructose-treated cells (Figure $2 \mathrm{~A}$ ). Whereas in MDA MB231 cells, the GHRH-R expression showed elevation in both $10 \%$ serum containing medium as well as with 15 $\mathrm{mM}$ fructose when compared with $0.5 \%$ serum containing medium but not with $15 \mathrm{mM}$ glucose treatment (Figure 2B). Treating cells with $15 \mathrm{mM}$ glucose might cause osmotic pressure, which possibly leads to unsought effect; therefore, $15 \mathrm{mM}$ of fructose was used to count for the osmotic pressure variable. 
Citation: Awad SHA, Ibrahim MEEAEAM, Khan GF, Ahmed SBM (2018) GHRH-R Expression Level under Hyperglycaemic Like Culture Conditions in Breast Cancer Cell Lines. Biol Med (Aligarh) 10: 428. doi:10.4172/0974-8369.1000428

Page 3 of 5

\section{The impact of hyperglycemia on breast cancer cell lines proliferation}

To investigate whether GHRH-R expression variation under hyperglycemic conditions affects cell proliferation, MTT assays for proliferation were employed. T47D and MDA MB 231 were starved and then exposed to different conditions for $24 \mathrm{hrs}$ (10\% serum, $0.5 \%$ serum, $0.5 \%$ serum $15 \mathrm{mM}$ glucose and $0.5 \%$ serum $+15 \mathrm{mM}$ fructose). The cell proliferation and viability were then assessed by colorimetric MTT assays. Addition of $10 \%$ serum to the media had significantly enhanced cell proliferation $(\mathrm{p}<0.05)$ in both cell lines, whereas glucose treatment was unable to increase cell proliferation rate in both cell lines (Figure 3). Accordingly, it was deduced hyperglycemia had no significant effect on the proliferation of the two-tested breast cancer cell lines.

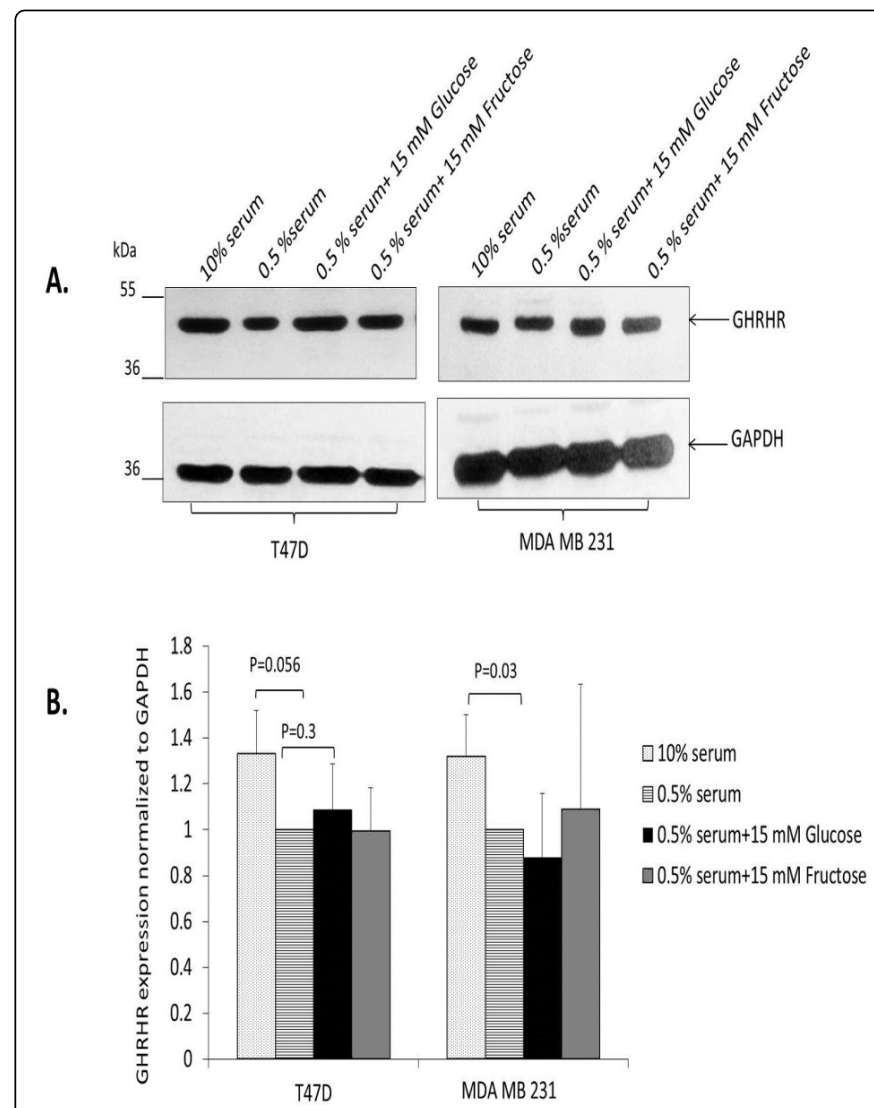

Figure 1: The effect of hyperglycemia in GHRH-R expression in T47D and MDA MB 231. (A): T47D and MDA MB 231 were starved for $24 \mathrm{hrs}$ and then exposed to different conditions for 24 hrs ( $10 \%$ serum, $0.5 \%$ serum, $0.5 \%$ serum $+15 \mathrm{mM}$ glucose and $0.5 \%$ serum $+15 \mathrm{mM}$ fructose). The cells were lysed, and protein extracts were resolved on a $10 \%$ SDSPAGE gel. Immunoblotting was performed by anti-GHRH-R antibody (1:2000) and anti-GAPDH antibody. (B): The bottom panel demonstrates the expression levels of GHRH normalised to GAPDH expression from A. The analysis of the band intensity was done by image $\mathrm{J}$.

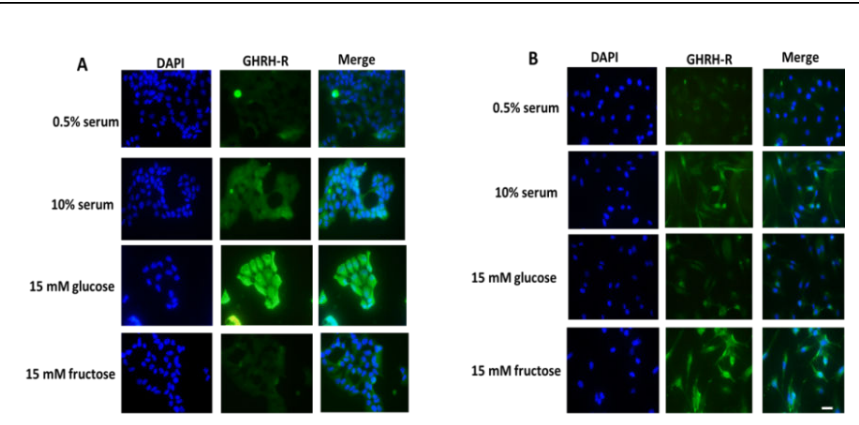

Figure 2: Assessing GHRH-R expression in MDA MB 231 and T47D breast cancer cell lines by immunofluorescence. The T47D (A) or MDA MB231 (B) cells were seeded on coverslips for $24 \mathrm{hrs}$. This followed by serum starvation of cells for $24 \mathrm{hrs}$. The cells were either left starved (incubated with $0.5 \%$ serum containing medium), incubated with $10 \%$ containing medium, incubated with $0.5 \%$ serum containing medium plus $15 \mathrm{mM}$ glucose or incubated with $0.5 \%$ serum containing medium plus $15 \mathrm{mM}$ fructose. The cells were fixed with $3.8 \%$ formaldehyde, saturated and permeabilised with $0.1 \%$ Triton. The GHRH-R antibody was then added, and this was followed by its detection by the addition of anti-Rabbit IgG H\&L (Alexa Fluor ${ }^{\circledR} 488$ ) for $1 \mathrm{hr}$ at room temperature. The coverslips were finally mounted and sealed. The cells were visualised by fluorescence microscope (Olympus, BX51TF) using cellSens Standard software. The scale bar represents $6.4 \mu \mathrm{M}$.

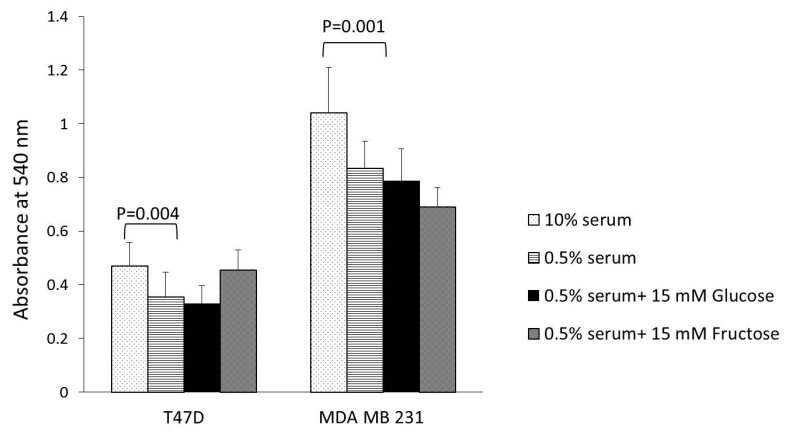

Figure 3: T47D and MDA MB 231 proliferation under hyperglycemic conditions. T47D and MDA MB 231 were starved for $24 \mathrm{hrs}$ and then exposed to different conditions (10\% serum, $0.5 \%$ serum, $0.5 \%$ serum $+15 \mathrm{mM}$ glucose and $0.5 \%$ serum $+15 \mathrm{mM}$ fructose) for $24 \mathrm{hrs}$. The colorimetric MTT assay was used to assess cell proliferation. Error bars represent standard error of mean, P: probability by student $\mathrm{t}$-test in comparison between $10 \%$ serum and $0.5 \%$ serum. GHRH-R: growth hormone releasing hormone receptor, GAPDH: glyceraldehyde-3-phosphate dehydrogenase.

\section{The correlation between GHRH-R expression and the proliferation of the tested breast cancer cell lines}

In order to conclude the exact relation between GHRH-R expression levels and breast cancer cell lines proliferation Pearson correlation coefficient factor was calculated. No significant correlation was revealed (Table 1). The correlation was calculated between GHRH- 
$\mathrm{R}$ expression levels, obtained from western blotting after normalization, and cell proliferation that was measured by MTT assay. Pearson correlation coefficient was calculated using Microsoft Excel 2010.

\begin{tabular}{|l|l|l|}
\hline \multicolumn{3}{|c|}{ Pearson's correlation } \\
\hline & \multicolumn{1}{|c|}{ T47D } & \multicolumn{1}{c|}{ MDA MB 231 } \\
\hline $10 \%$ serum & 0.998897 & 0.999377 \\
\hline $0.5 \%$ serum & 1 & 1 \\
\hline $15 \mathrm{mM}$ glucose & -0.22623 & -0.4742 \\
\hline
\end{tabular}

Table 1: The correlation between GHRH-R expression and cell proliferation. Correlation was calculated between GHRH-R expression levels, obtained from western blotting after normalization, and cell proliferation that was measured by MTT assay. Pearson correlation coefficient was calculated using Microsoft Excel 2010.

\section{Discussion}

Diabetes Mellitus (DM) is disease of an array of disorders characterized by hyperinsulinemia, hyperglycemia, and different metabolic alterations [14]. Thereby, DM can negatively affect the cell machinery, which might lead to various disorders such as neuropathy, nephropathy and of recent few evidences had shown that DM predisposes to cancer development and progression. It was shown that pancreatic, liver and kidney cancers development have strong association with diabetes [3]. In addition, women with diabetes are more vulnerable to develop endometrial and breast cancer [6]. Regrettably, it is not only the cancer development risk that increases with DM, but also the mortality [15]. The exact molecular mechanism of how DM plays role in cancer development is obscure. Therefore, it is of a particular interest to study how DM mediates cancer development and progression. GHRH-R was found to mediate cell viability and proliferation in different types of cancer [16,17]. Accordingly, a question came to our mind; could GHRH-R be one of the mechanisms that DM utilizes to facilitate cancer cell proliferation?

Although our results didn't show striking correlation between cell proliferation and GHRH-R expression under hyperglycemic-like conditions, treatment with $10 \%$ serum was able to induce GHRH-R expression as well as mediate cell proliferation (Pearson's correlation 1). Serum contains abundance of growth factors and hormones such as thyroid hormone and insulin-like growth factors [18], which might have contributed to GHRH-R over expression in $10 \%$ serum treatment. Furthermore, it is of interest to test whether addition of $10 \%$ serum or hyperglycemic-like conditions affects GHRH-R function via increasing the intracellular levels of cAMP. However, it was shown that hyperglycemia promotes GHRH-R expression in short exposure of GHRH-R; prolonged exposure to hyperglycemia was proved to negatively affect the functionality of the GHRH-R in a diabetic rat model [13]. This necessitates investigating the functionality of GHRH-R by dissecting the downstream signalling pathways associated with GHRH-R, which might explain the nonproliferative effect of GHRH-R under the hyperglycemic conditions.

Some of our data showed that $15 \mathrm{mM}$ glucose had negatively affected the cell proliferation and GHRH-R expression; we thought this might be due to glucotoxicity [19]. Contrary, a previous study investigated the effect of high glucose environment, used concentration from $5.5 \mathrm{mM}$ to $50 \mathrm{mM}$, and showed an increase in pancreatic cancer cell proliferation [20]. Therefore, it would be sensible to use lower glucose concentrations for longer periods in order to avoid any toxic effect of high glucose as well as attempting to mimic what happens in diabetic patient's cells. Concentrations ranging from 7 to $11.1 \mathrm{mM}$ would be more reliable to use since hyperglycemia is defined as fasting glucose level of $126 \mathrm{mg} / \mathrm{dl}(7 \mathrm{mmol} /$ liter $)$ or a random blood glucose level of $200 \mathrm{mg} / \mathrm{dl}$ (11.1 mmol/liter) [21].

Since different factors are responsible to cause DM pathology, it is crucial to apply hyperinsulinemia along with hyperglycemia to investigate GHRH-R expression in correlation with cell proliferation. Furthermore, the association between hyperinsulinemia and breast cancer was established previously by Bruning and et al. [22]. On the other hand, fructose was used as control to count for the osmotic pressure variable, though it shows effect on the cell proliferation at a time. Fructose is known to be a substrate for pentose phosphate pathway (PPP), thereby it influences nucleic acid synthesis [23], this might explain the seen effect of fructose in cancer cell proliferation. Based on this, it was thought that in future experiments it would be more convenient to use mannitol albeit fructose was extensively employed for that purpose by other previous research.

\section{Conclusion}

GHRH-R expression was found to be induced by growth factors and hormones presence, while hyperglycemia had no effect on GHRH-R expression. Our results suggest that GHRH-R might mediate breast cancer cells proliferation and survival via other factors. Even though hyperglycemia is associated with increased proliferation, this was not the case in our study where we conclude that hyperglycemia alone does not increase cancer cells proliferation, which suggests that other conditions associated with hyperglycemia (e.g. hyperinsulinemia) could be mediating increased proliferation. Further detailed studies are required to answer how diabetes mellitus disease state alters the cell machinery to yield distorted cells like in cancer.

\section{Conflict of Interest}

The authors declare no conflict of interest.

\section{Funding}

This work would not have been accomplished without Boehringer Ingelheim financial support.

\section{Acknowledgement}

Our sincere thanks go to Professor Taleb Al-tal, the research director of Sharjah Institute for medical research, for his continuous support.

\section{References}

1. Ryu TY, Park J, Scherer PE (2014) Hyperglycemia as a risk factor for cancer progression. Diabetes Metab J 38: 330-336.

2. Cannata D, Fierz Y, Vijayakumar A, LeRoith D (2010) Type 2 diabetes and cancer: what is the connection? Mt Sinai J Med 77: 197-213.

3. Giovannucci E, Harlan DM, Archer MC, Bergenstal RM, Gapstur SM, et al. (2010) Diabetes and cancer: a consensus report. Diabetes Care 33: 1674-1685.

4. Perseghin G, Calori G, Lattuada G, Ragogna F, Dugnani E, et al. (2012) Insulin resistance/hyperinsulinemia and cancer mortality: the Cremona study at the 15th year of follow-up. Acta Diabetol 49: 421-428. 
Citation: Awad SHA, Ibrahim MEEAEAM, Khan GF, Ahmed SBM (2018) GHRH-R Expression Level under Hyperglycaemic Like Culture Conditions in Breast Cancer Cell Lines. Biol Med (Aligarh) 10: 428. doi:10.4172/0974-8369.1000428

Page 5 of 5

5. Rosato V, Tavani A, Gracia-Lavedan E, Guino E, Castano-Vinyals G, et al. (2016) Type 2 Diabetes, Antidiabetic Medications, and Colorectal Cancer Risk: Two Case-Control Studies from Italy and Spain. Front Oncol 6: 210.

6. Vigneri P, Frasca F, Sciacca L, Pandini G, Vigneri R (2009) Diabetes and cancer. Endocr Relat Cancer 16: 1103-1123.

7. Lin-Su K, Wajnrajch MP (2002) Growth Hormone Releasing Hormone (GHRH) and the GHRH Receptor. Rev Endocr Metab Disord 3: 313-323.

8. Chatzistamou I, Schally AV, Kiaris H, Politi E, Varga J, et al. (2004) Immunohistochemical detection of GHRH and its receptor splice variant 1 in primary human breast cancers. Eur J Endocrinol 151: 391-396.

9. Chatzistamou I, Volakaki AA, Schally AV, Kiaris H, Kittas C (2008) Expression of growth hormone-releasing hormone receptor splice variant 1 in primary human melanomas. Regul Pept 147: 33-36.

10. Garcia-Fernandez MO, Schally AV, Varga JL, Groot K, Busto R (2003) The expression of growth hormone-releasing hormone (GHRH) and its receptor splice variants in human breast cancer lines; the evaluation of signaling mechanisms in the stimulation of cell proliferation. Breast Cancer Res Treat 77: 15-26.

11. Havt A, Schally AV, Halmos G, Varga JL, Toller GL, et al. (2005) The expression of the pituitary growth hormone-releasing hormone receptor and its splice variants in normal and neoplastic human tissues. Proc Natl Acad Sci U S A 102: 17424-17429.

12. Barabutis N, Schally AV (2008) Knocking down gene expression for growth hormone-releasing hormone inhibits proliferation of human cancer cell lines. Br J Cancer 98: 1790-1796.

13. Bedard K, Strecko J, Theriault K, Bedard J, Veyrat-Durebex C, et al. (2008) Effects of a high-glucose environment on the pituitary growth hormone-releasing hormone receptor: type 1 diabetes compared with in vitro glucotoxicity. Am J Physiol Endocrinol Metab 294: E740-751.

14. Kahn SE, Cooper ME, Del Prato S (2014) Pathophysiology and treatment of type 2 diabetes: perspectives on the past, present, and future. Lancet 383: $1068-1083$.
15. Ranc K, Jorgensen ME, Friis S, Carstensen B (2014) Mortality after cancer among patients with diabetes mellitus: effect of diabetes duration and treatment: (questionable) classification of diabetic patients based on combination of specific glucose-lowering drugs. Reply to Holden SE, Bannister CA, Currie CJ [letter]. Diabetologia 57: 2003-2004.

16. Gan J, Ke X, Jiang J, Dong H, Yao Z, et al. (2016) Growth hormonereleasing hormone receptor antagonists inhibit human gastric cancer through downregulation of PAK1-STAT3/NF-kappaB signaling. Proc Natl Acad Sci U S A 113: 14745-14750.

17. Munoz-Moreno L, Arenas MI, Carmena MJ, Schally AV, SanchezChapado M, et al. (2016) Anti-proliferative and pro-apoptotic effects of GHRH antagonists in prostate cancer. Oncotarget 7: 52195-52206.

18. Brunner D, Frank J, Appl H, Schoffl H, Pfaller W, et al. (2010) Serum-free cell culture: the serum-free media interactive online database. ALTEX 27: 53-62.

19. Lorenzi M, Cagliero E, Toledo S (1985) Glucose toxicity for human endothelial cells in culture. Delayed replication, disturbed cell cycle, and accelerated death. Diabetes 34: 621-627.

20. Han L, Ma Q, Li J, Liu H, Li W, et al. (2011) High glucose promotes pancreatic cancer cell proliferation via the induction of EGF expression and transactivation of EGFR. PLoS One 6: e27074.

21. American Diabetes Association (2008) Diagnosis and classification of diabetes mellitus. Diabetes Care 31: S55-60.

22. Bruning PF, Bonfrer JM, van Noord PA, Hart AA, de Jong-Bakker M, et al. (1992) Insulin resistance and breast-cancer risk. Int J Cancer 52: 511-516.

23. Liu H, Huang D, McArthur DL, Boros LG, Nissen N, et al. (2010) Fructose induces transketolase flux to promote pancreatic cancer growth. Cancer Res 70: 6368-6376. 